\title{
Management of Risk in Deep Foundations with Design-Build
}

\author{
Dan Brown ${ }^{1}$, M.ASCE, Ph.D., P.E.
}

\author{
${ }^{1}$ President, Dan Brown and Associates, PLLC, 300 Woodland Road, Sequatchie, TN 37374; \\ Phone: 423-942-8681; dbrown@danbrownandassociates.com
}

\begin{abstract}
The design-build delivery system is receiving increased use on large infrastructure projects, and deep foundations often represent a significant component of the risks to project costs and schedule. This paper presents a discussion of the management of the risk elements associated with the design and construction of deep foundations, along with some strategies that have been employed to help mitigate these risks. The effective management of risks with deep foundation design and construction is seen to require cooperative effort, particularly between the constructors and designers, and an ability to evaluate the problem from a broad perspective. Test programs can be utilized to develop mitigation strategies and reduce risks relative to both performance and productivity.
\end{abstract}

\section{INTRODUCTION}

Design-build has become a preferred method of project delivery for many large construction projects. There may be numerous factors leading to the choice of design-build by the owner, but perceived advantages with respect to schedule and costs are often major considerations. With respect to deep foundation design and construction, the design-build team must take on the responsibility to deliver foundations which satisfy the performance criteria set by the owner and meet other requirements for support of the structure.

Inherent to this responsibility, are the risks the design-builder takes with respect to the design, construction, and performance of deep foundations. These risks must be assessed and managed effectively in order to develop a winning proposal and achieve a successful project. A successful project would be one which is financially rewarding to the design-builder, achieves the performance required, and is delivered on-time to the owner.

This paper outlines some of the risk components and possible mitigation strategies associated with design and construction of deep foundations in the designbuild environment. The paper is presented from the point of view of the designbuilder and with emphasis on infrastructure projects. The risks inherent in designbuild with large infrastructure projects can be substantial with respect to both direct 
costs and schedule. Failure to adequately address risks can lead to increased costs, schedule impacts, poor performance, and financial losses.

The issue of risk must be confronted by all stakeholders in the design-build project, including the constructors, the design professionals, and the owners. Constructors are confronted with risks inherent to the nature of their work with conventional construction, but the design element presents new challenges unique to the design-build delivery system. Most geotechnical design professionals have traditionally been very "risk-averse" (i.e., cautious and conservative) in the design of deep foundations, and with good reason; the conventional design-bid-build system offers little incentive for efficiency compared to the penalty for failure. However, the competitive nature of the bidding process with major public works projects represents an unusual environment for most geotechnical engineers, and an overly conservative assessment of risks on the part of the design-build team can result in an unsuccessful proposal/bid. Project owners have a stake in the management of risk by the designbuilder because of the possible negative impact of schedule delays or costs associated with litigation and/or claims related to differing site conditions. Thorough pre-bid geotechnical investigations and/or foundation testing by the owner can reduce risk to the design-builder during bidding and therefore reduce contingency costs and lower bid prices.

In order to manage risks effectively, significant risks must be identified and their potential impact assessed, a plan for possible mitigation of the risks developed, and an appropriate allocation for the costs associated with the risks included in the bid.

\section{IDENTIFICATION AND ASSESSMENT OF RISKS}

During the design-build proposal process, a preliminary deep foundation design must be completed in order to develop a technical proposal, a work plan and tentative schedule, and cost estimate. The proposal stage is the most critical time to develop an initial assessment of risks, and this task often must be completed in a short time with limited subsurface information. Some of the more significant risk items are included in the following categories.

Stratigraphy. Variability in stratigraphy across the site may affect deep foundation length requirements and costs. Variability may be difficult to accommodate with some types of deep foundations. A potential for unusual depth in some locations may preclude some foundation types from consideration. Variability increases the need for additional borings or soundings, and this work can affect the project schedule. Examples include variable depth to top of rock, voids due to weathering or solution activity, or variable depth to bearing stratum due to alluvialfilled channels. One method to assess the impact of stratigraphy is to estimate the potential range of variations in stratigraphy across the project site, along with the likely numbers of foundation units falling within the spectrum of possibilities. Another approach might be to develop a design for the range of possible conditions and then assign probabilistic values to the most likely, most unfavorable, and most favorable conditions. When the available geotechnical data are sparse, these approaches generally include a fair amount of engineering judgment combined with a dose of guessing (do you feel lucky?). 
As an example, a design-build project for a bridge along the Gulf Coast consisted of several miles of elevated roadway extending between the mainland and a barrier island beachfront community. A design-build team composed of a regional engineering firm, a regional bridge contractor, and a regional pile driving contractor was assembled and "short-listed" to bid the work. Each of these firms was a well-run organization and highly respected in their field. The project was a relatively straightforward job, to consist of repetitive spans with precast concrete girders supported on prestressed piles; however, there were only a few borings across several miles of distance. The depth to good bearing soils was variable and therefore the anticipated pile length could not be predicted except within a broad range. Because of the size of the project and the magnitude of the downside risk, this design-build team elected not to tender a bid. The project was awarded to a much larger contractor with greater resources. Because the project owner left most of the site investigation work to the post-award effort of the design-builder, the resulting risk eliminated a team of local engineers and constructors who were very well qualified to perform the work at a competitive price. The cost of borings can be estimated fairly easily; the cost of a lack of borings is more difficult to quantify in this case.

Foundation Performance. Uncertainties in material behavior of soil or rock can affect anticipated foundation performance and construction techniques or productivity. Examples include uncertainties relating to measurements of performance as required by contract or as proposed with a value-engineering cost proposal. Besides conventional static load tests, dynamic tests are often required for verification on driven pile projects, and unanticipated results such as large setup or unusually low indicated resistance can lead to production delays and/or additional testing requirements. Measurements require interpretation to evaluate foundation performance, and foundation performance risks to the design-builder are increased by an owner or owner's representative who insists on extremely narrow or inappropriate interpretations of measurements. Where foundation performance risks are identified as significant, it is helpful to assess the range of potential behavior and the potential impact on the project costs or schedule.

Construction Productivity. Effects of material behavior on construction techniques or productivity can have a huge impact on costs and time. Examples include drivability of driven piles, difficulties in rock excavation or boulders with drilled shafts, effects of artesian groundwater or caving soils, potential ground subsidence with continuous flight auger piles, and impacts of solution cavities on construction of all types of deep foundations. Productivity is most often estimated on the basis of experience in similar geology or circumstances. The assessment of the possible range of productivity with different construction techniques and the risk elements in this category is most effectively performed by a team of constructors, estimators, and geotechnical/structural engineers. By working cooperatively in brainstorming sessions, a group can bring the broadest possible perspectives to the problem and intelligently assess risk components with each potential foundation type or installation method.

Construction Defects. Defects which must be corrected can lead to significant costs and delays in some instances. Issues such as broken or out-of-position piles, or 
concrete defects in drilled shafts represent potential risks to the design-builder. Excessive inspection and quality assurance requirements from the owner can greatly increase the risks to the design-builder, such as low tolerances on drilled shaft bottom cleanliness, inappropriate interpretation of integrity test results, or excessive demands for restrike measurements on driven piles. As with productivity, an assessment of risks of defects, probability of occurrence, and the potential impact should be included with each foundation alternative.

\section{MITIGATION STRATEGIES}

Once the most significant risks are identified and the magnitude assessed, mitigation strategies may be developed to reduce the negative consequences of risk to the design-builder. Strategies can include transfer of the risk to some other party or reduction of risk with a different approach. Engineered solutions may be developed to reduce risk with better or more reliable information or with a more robust foundation design or construction approach that will reduce the impact.

Risk Transfer. Transfer of risk from the design-builder to an outside party can be accomplished with the purchase of insurance, but this approach is not typically employed for the deep foundation component of a construction project. A more common approach is to seek to transfer some level of risk back to the project owner through negotiated exception clauses included in the bid or through claims. Exception clauses may be negotiated between the design-builder and the project owner, both of whom must agree with contract stipulations. Exceptions can cause a cost proposal to be considered "non-responsive" on many competitively bid public works projects and therefore may not be possible in many instances. Claims for differing site conditions or other changes provide a means of mitigating unusual variations in conditions.

Differing site conditions clauses (FHWA, 1996) are intended to provide a means for constructors to recover costs associated with conditions that could not reasonably have been anticipated at the time of bidding, and therefore eliminate the need for the bidder to include contingency costs for items which presumably could not have been anticipated anyway. However, claims for differing site conditions (DSC) or other changes can be expensive to pursue and can result in lengthy delays of reimbursement for costs or even risks of non-reimbursement for costs if the owner disagrees. With design-build, it is generally expected that DSC or other changes are truly "unanticipated" and therefore represent risks or deviations beyond the range of conditions that reasonable and responsible bidders would anticipate. To this end, it is desirable that the geotechnical professionals document the anticipated range of conditions as described in the previous section so that a claim can be more effectively be presented should the need arise. A pre-bid design based on an unreasonably narrow range of conditions does not provide an effective mitigation strategy.

Mitigation of Stratigraphy Risks. The owner can often provide the most effective measures to mitigate risks of subsurface variability by executing a more extensive pre-bid site investigation. The design-builder may decide to conduct additional site investigation pre-bid to mitigate risk of uncertainty, but the time available to do so is limited and the costs must be weighed against the uncertain 
prospects of winning the job. A relatively modest investment in site exploration on the part of the owner can pay great dividends in terms of reduced contingency costs in the bids and reduced risk of claims for differing site conditions.

The geotechnical baseline report (GBR) as a basis for bidding has been used successfully for tunnel projects, which have a high degree of risk with respect to subsurface conditions. The GBR does not eliminate risk, but defines the extent of the risk to the constructor so that it can be more effectively quantified and budgeted. The use of this approach for deep foundations is encouraged by ASCE (2007), but to date the concept has been rarely used for deep foundations.

Post-award mitigation of stratigraphy risks may include additional site investigation, development of an adaptive foundation construction plan that allows adjustment to actual conditions encountered, or a combination of both.

After a design has been developed based on the overall geotechnical investigation, additional exploration might be performed solely for a specific purpose related to the foundation construction. Given that design-build projects are often executed with an aggressive schedule, the foundation design may be finalized as construction proceeds based on the actual conditions encountered. Examples of investigations that might be conducted concurrent with construction include:

- Exploratory borings at the location of each drilled shaft, drilled without sampling to determine depth to rock and then cored into rock to determine rock conditions and establish fnal tip elevation.

- Extensive coverage with CPT soundings or borings with SPT only to determine pile or shaft tip elevations at each foundation location.

- A test pile driven at each foundation location to more reliably define pile length requirements

The strategy employed must be consistent with the geology and the nature of the anticipated variations. For instance, drilled shafts constructed in karst formations typically require more extensive investigation at each shaft location to depths below the anticipated tip elevation to finalize each specific shaft design. Drilled shafts in rock from geologic conditions with less inherent variability might require only an evaluation of the depth of weathered rock at each specific shaft location.

The recently completed I-35W St. Anthony Falls bridge in Minneapolis was constructed with a very aggressive schedule in order to rebuild the structure which collapsed in 2007. The new bridge was founded on groups of drilled shafts constructed into the St. Peter Sandstone formation, a friable (poorly cemented) sandstone. Most of the axial resistance of the shafts is derived from side resistance in the sandstone, but the uppermost 3 to $8 \mathrm{~m}$ was typically weathered and soft. The measured side resistance and performance of the drill rig during the test shaft construction was used to develop a construction plan to accommodate variations. This plan included one or two borings at each shaft group location along with monitoring of the drill rig penetration rate during construction of each individual shaft. By careful observation of the drill rig performance during excavation of the sandstone, the depth of the soft, weathered sandstone could be readily distinguished 
from the relatively unweathered sandstone below. The final tip elevation of each shaft was then determined during construction on the basis of these observations.

A transmission line project in the western United States traversed a broad range of geology including relatively soft alluvial soils, as well as stronger cemented soils and rock. Design of the deep foundations was controlled by lateral and overturning loads. Foundations in the soft soils were designed for the worst case soil conditions anticipated within the soft alluvial soils based on the several borings made, and no additional exploration was performed in these areas. This approach was optimal for the alluvial soil conditions because: a) the schedule was very aggressive and the soft soil areas were on the critical path, b) the foundation design was sufficiently robust to accommodate variability, and c) no significant cost savings could be realized by trying to adjust the foundation length on a case-by-case basis. The construction equipment and installation methods were sized to handle the worst case conditions.

The foundations in the stronger soil and rock areas were designed for a baseline case representative of each geologic area from the pre-design borings. The specific shaft tip elevation at each foundation location was developed from a boring at each location, performed concurrent with the ongoing construction operation. The boring at each location is a fast and simple probe with SPT and visual classification only, and besides the design information this boring provides a means to identify rock or obstructions such as boulders.

Mitigation of Foundation Performance and Productivity Risk. Mitigation of foundation performance and productivity risks are discussed together, because the strategies employed usually can be directed toward both. The most effective means to reduce risks associated with productivity and performance is to conduct full-scale tests in representative ground conditions. When the owner conducts a pre-bid testing program, these risks can be minimized and bidders can eliminate much of the contingency costs associated with these risks. An example is the pre-bid program of axial and lateral load tests of drilled shafts into the Cooper Marl and overlying alluvium for the Cooper River Bridge in Charleston, SC (Brown et al, 2002; Camp et al, 2002). This project was subsequently awarded as a design-build contract, and the final selection of foundation type could be changed by the design-builder; however, the foundation type to be used (drilled shafts into the marl) was fairly obvious for this site. The potential savings to the project owner from pre-bid deep foundation test programs are difficult to quantify, and if a variety of deep foundation types or construction techniques are viable for the project then it may be preferable to leave the test shafts or piles for the design-builder to perform in a manner specific to their foundation design.

A design-builder may conduct their own pre-bid tests to evaluate foundation performance and productivity. At the pre-bid stage, the results are used not only to reduce risks and refine cost estimates, but also to gain competitive advantage. Drilled foundations in rock represent one type of deep foundations where there may be large potential variations in construction productivity and foundation performance, and where significant competitive advantage may be realized from pre-bid tests. Pre-bid tests may sometimes be conducted off-site in similar geology, or research to find test data from other projects in similar conditions may serve a similar purpose. In any 
case, the constructor and the geotechnical design professionals in a design-build environment should explore the possible benefits as a joint effort to develop the most cost-effective and efficient foundation solution.

A post-award testing program is often mandatory for verification of performance to the owner on major projects, but with careful planning, test foundations can be highly beneficial in mitigating risks. Foundation testing is affected by both the compressed schedule associated with design-build and the shared interest of the geotechnical designer and constructor to mitigate risks associated with performance and productivity. The test pile program must usually be initiated concurrent with the final site investigation and geotechnical design efforts, and therefore it is desirable that a plan be developed during the pre-bid stage so that implementation can proceed soon after notice to proceed.

The recently completed Biloxi Bay Bridge provides an example of an extensive test pile program which was used to mitigate risks of performance and productivity. The bridge across Biloxi Bay, destroyed by Hurricane Katrina, was to be replaced with a new structure constructed on driven prestressed concrete piles. The schedule was very aggressive, and included both early completion bonuses and liquidated damages for late delivery. In this case, the greatest risk factor was that variable pile lengths requiring extensive restrike measurements or pile splices might affect the schedule. A relatively few borings were available pre-bid and the debris from the old bridge impacted the schedule of completion of new borings.

A testing program consisting of 20 test piles (approximately every $4^{\text {th }}$ pier) spread across the bay was initiated as the site exploration was ongoing. Early borings were concentrated at the planned locations of test piles so that estimated tip elevations for these piles could be developed and piles cast as quickly as possible. Because of the storm damage, the local prestressing plant was not yet operating a full capacity and there was great demand for their product for reconstruction elsewhere in the area (notably the local casinos); therefore it was imperative to start casting piles quickly and continue to cast piles for the bridge at a steady pace. Soil conditions consisted of a highly variable mix of interbedded sands and clays.

The test piles were completed with dynamic measurements, and restrike measurements were performed for dynamic load tests over a period of up to two months after the initial pile installation. One static axial load test and two rapid load tests (using the Statnamic device) were also performed to validate the static axial resistance indicated by the dynamic load tests. Two lateral load tests were performed to verify lateral soil resistance for design. A key component of the test measurements were the verification of the increase in axial resistance as a function of time across the broad range of conditions across the bay. The test piles also verified that the pile installation equipment selected for the project could install the piles without damage for a wide range of conditions and even install the piles through soils with an axial resistance significantly greater than the design requirements.

Because the end bearing resistance was highly variable, a foundation design reliant upon this component of resistance would have resulted in significant variations in pile length and challenges in achieving required driving resistance 
during installation without splices or cutoffs. Therefore, the foundation design and target pile tip elevation at each pier was based on the resistance of those piles which did not have large end bearing resistance. Where substantial base resistance was indicated from the signal matching of restrike blows (based on analyses from CAPWAP), the resistance was discounted to that measured by piles without high end bearing. In almost all cases, the pile driving system was able to achieve penetration without refusal and the need for cutoffs. Based on the setup indicated by extensive restrike measurements available from the test pile program, driving criteria for production piles were easily achieved and even relatively low driving resistance observed during installation did not require restrike measurements. The need to restrike production piles was largely avoided; restrikes would require repositioning of barges, disrupt productivity, and adversely affect the schedule.

The design-build contract for the Biloxi Bay Bridge was awarded in June, 2006 and the bridge opened to traffic in October, 2007, 2 weeks ahead of schedule. The State of Mississippi was pleased, the people of Biloxi were pleased and the constructor was pleased (translation: incentive bonus was achieved). The test pile program for this project was instrumental in maintaining productivity and completing the bridge on schedule.

Mitigation of Construction Defect Risks. There will always be some risks of construction defects related to equipment failures, acts of nature, and fallible human beings. From a geotechnical design and construction perspective, the most effective means of reducing risks from construction defects is to develop a robust design and construction plan with an emphasis on "design for constructability". The best foundation design is one which is easy to construct, and the best installation plan is one which does not push the limits of equipment capabilities. In many instances, a test installation or load test program can be used to improve both the design for constructability and the methods used for installation.

An example of the use of a test shaft to mitigate the risk of construction defects is provided by the drilled shaft load tests for the new Christopher Bond Memorial Bridge across the Missouri River in Kansas City. The main pylon for this cable stayed bridge was founded on a group of 8 drilled shafts, each $3.2 \mathrm{~m}(10.5 \mathrm{ft})$ diameter and extending through approximately $30 \mathrm{~m}(100 \mathrm{ft})$ of overburden to penetrate $8 \mathrm{~m}(26 \mathrm{ft})$ into shale. A permanent casing was installed through the river and overburden to the shale. This shale, like many shales, is prone to decompose rapidly when exposed in the shaft excavation. For this reason, the standard MoDOT specification includes a restrictive time limit on the period for which the shaft rock socket excavation may be open if the design relies on side resistance for axial capacity. The time required to complete the hole cleanout, install the reinforcement, and start concrete placement in the large diameter and deep shafts on this project would exceed the time allowed by specification and result in a constructed shaft which was considered not in conformance with the project requirements.

Slake durability tests were performed on shale taken from core samples using both water and a solution of polymer drilling slurry. These tests suggested that the use of polymer slurry reduced the tendency of the shale to quickly decompose compared to the use of water alone. Although the permanent casing to rock would 
allow the shafts to be constructed with water rather than slurry, the polymer appeared to provide advantages with respect to decomposition of the shale. Therefore the test shaft was designed to be constructed using polymer slurry and, pending favorable results, polymer slurry was planned for production shafts.

A $1.8 \mathrm{~m}(6 \mathrm{ft})$ diameter prototype load test shaft was constructed to measure axial resistance in the shale in side shear and base resistance using an embedded bidirectional load cell (O-cell). In order to establish a basis for construction of production shafts, the test shaft was drilled with polymer slurry and left open for a period of four days prior to completion and concrete placement. The load test results indicated side and base resistance of this test shaft slightly higher than the design parameters estimated pre-bid, and the special provisions for production shafts were modified to allow up to four days to start concrete placement in the shaft after completion of the rock excavation. This modification to the specification subsequently proved to be very valuable when a drilling tool malfunctioned during construction of one of the production shafts. The 1.5 days of delay associated with extraction of this tool and repair of the equipment was accommodated by the revised specification, thanks to the demonstrated performance of the load test shaft.

Another example of a robust design of a drilled shaft which can reduce the risk of defects is the use of base grouting at the toe of a shaft (Dapp, et al, 2006). Although often used as a means to improve the base resistance of a shaft in granular soil, the use of base grouting has been demonstrated to mitigate the effects of imperfect bottom cleaning operations. Many agencies have specifications with tolerance on loose material at the base of the shaft which can be difficult or impossible to achieve in large diameter and very deep drilled shafts under slurry. The delivery of grout under pressure at the toe of the shaft has been demonstrated by load tests to mitigate the effects of imperfect cleaning and justify a relaxation of the tolerances on bottom cleanout.

The use of full length segmental casing for drilled shaft construction installed with a rotator or oscillator system can reduce the risk of construction defects in certain conditions. Where the risk of hole collapse is high and the consequences are especially severe (such as near an existing structure), the full length casing helps mitigate the risk of instability. Risks associated with delays or difficulties with alignment and excavation stability posed by obstructions such as boulders or buried logs can be reduced because the casing is used like a coring tool to cut through such obstructions. One contractor's internal documentation of integrity test measurements indicates that the incidence of "anomalies" in drilled shaft concrete is reduced in shafts constructed with this method. The full length casing typically allows concrete to be placed in the dry or in a water-filled excavation as opposed to a slurry excavation which may have a greater quantity of suspended particles.

On a recent project in the southeast, the constructor was placing concrete with a tremie in a shaft which was $2.4 \mathrm{~m}(8 \mathrm{ft})$ diameter and over $60 \mathrm{~m}(200 \mathrm{ft})$ deep. A failure of the tremie occurred when the shaft was approximately one third completed. Because the shaft was constructed using the oscillator method with full length casing, the casing was re-advanced to the bottom of the original excavation, the concrete removed with an air-lift, the reinforcement recovered, and the shaft reconstructed in 
the same excavation a few days later. Although the removal of concrete and re-do of the shaft was expensive, the problem of the repair of a shaft with a structural defect was avoided thanks to the excavation stability provided by the segmental casing method.

\section{COSTS ALLOCATED TO RISKS}

As a final part of the pre-bid management of risks, a cost must be included in the bid to allow for some magnitude of adverse conditions encountered in the design and construction of deep foundations. In order to manage these costs effectively, a typical strategy is that the individual risk components are estimated, along with a cost impact and an estimated probability of occurrence so that the estimators can make an appropriate allowance. For example, if there are 10 elements of risk, each of which might have a $\$ 1$ million impact, and the probability of each is estimated at $30 \%$, it would be appropriate to include a $\$ 3$ million contingency cost in the bid. If these probabilities are estimated realistically, it is unlikely that all 10 elements would be realized on the project. A single large risk item would not be treated in such a simplified manner.

Because the pre-bid design is typically completed with incomplete information, the estimates of variability and the assessment of costs are imperfect; these facts must be acknowledged and accepted by all parts of the design-build team. It is important that the constructor not harbor unrealistic expectations of the geotechnical designers to "peer into their crystal ball" and see into the unknown. It is also not appropriate for the geotechnical design professionals to take the most pessimistic view of each possible aspect and therefore add conservatism on top of conservatism.

A bridge was planned across a waterway in a northern location, with foundations to be constructed of drilled shafts constructed through the water and socketed into the underlying hard rock. The design of the shafts was controlled by lateral and uplift resistance because of lateral forces from ice. The rock was extremely hard and abrasive, but the site included several old faults in which extensive fractures could be anticipated. The locations where fractures might be encountered were not known.

Two designs were developed, one for conditions where sound rock might be encountered and another (plan "B") for conditions where highly fractured rock might be encountered. The latter condition would require significantly deeper sockets as well as additional effort and time for installation. The geotechnical professionals (engineers and geologists) developed an estimate that $20 \%$ of piers (at unknown locations) might encounter the "plan B" conditions and the design-build constructor prepared a bid with the appropriate costs.

\section{SUMMARY AND CONCLUSIONS}

The design-build method of project delivery has seen increasing use on large infrastructure projects with extensive deep foundation components. The management of risk related to deep foundation design and construction is a key component of a successful project, and one which affects all of the stakeholders including the constructors, geotechnical professionals, and project owners. The effective management of risks with deep foundation design and construction requires 
cooperative effort, particularly between the constructors and designers, and an ability to see the problem from a perspective beyond one's own traditional perspective. Mitigation strategies can be developed with proactive thinking and particularly with utilization of testing programs which are designed with both performance and productivity risks in mind.

\section{ACKNOWLEDGMENTS}

The author wishes to acknowledge the helpful dialog and thoughtful discussions of the issues described in this paper by the following individuals: Mr. Steve Saye, Kiewit Engineering; Mr. Heinrich Majewski and Mr. Terry Tucker, Malcolm Drilling; Mr. Pat Byrne, Massman Construction; Mr. Frank Daams and Mr. Terry Poole, Flatiron Constructors; Mr. Brian Christenson, Black \& Veatch; Mr. Rich Lamb, Minnesota DOT; and Mr. Jeff Gebhard, Braun Intertec.

\section{REFERENCES}

American Society of Civil Engineers (2007). "Geotechnical Baseline Reports for Construction: Suggested Guidelines." R. Essex, editor, 72 p.

Brown, D. A. and Camp, W.M., 2002. "Lateral Load Testing Program for the Cooper River Bridge, Charleston, SC" Geotechnical Special Publication No. 116, ASCE, pp. 95-109.

Camp, W.M., Mayne, P.W., and Brown, D.A. 2002. "Drilled Shaft Axial Design Values: Predicted Versus Measured Response In A Calcareous Clay" Geotechnical Special Publication No. 116, ASCE, pp. 1518-1532.

Dapp, S., M. Muchard, and D. Brown, 2006. "Experiences with Base-Grouted Drilled Shafts in the Southeastern United States" Proceedings of the $10^{\text {th }}$ International Conf. on Piling and Deep Foundations, Amsterdam, June, 2006.

Federal Highway Administration (FHWA) (1996). "Geotechnical Differing Site Conditions." Geotechnical Engineering Notebook Issuance GT-15, Washington D.C., 37 p. 